\section{Aplicação Especial de Inseticidas em Saúde Pública}

A aplicaf̧ão espacial de inseticidas iniciada por Gorgas e Oswaldo Cruz, perdeu importância com o aparecimento do $D D T$, mas voltou a ser usada com o desenvolvimento dos inseticidas fosforados de baixa toxicidade. Nessa fase, entretanto, o nivel tecnológico é diferente. $O$ avião e o helicóptero permitiram a nebulização de inseticidas sob forma de produto técnico e, em seguida, apareceram máquinas portáteis e transportadas em viaturas capazes de realizar essa tarefa. Pouco demorou para que fosse resolvido o problema do tamanho das gotas que, para mosquitos, tem que ser inferior a $20 \mu$ Essas aplicaçôes a ultrabaixo volume (UBV) começaram a ser usadas no Brasil contra Culex quinquefasciatus e seu uso foi incrementado depois da reintrodução, no pais, de Aedes aegypti Uma série de trabalhos experimentais visando a um método de fazer baixar, rapidamente. a densidade desse mosquito foi iniciada pela Superintendência de Campanhas de Saúde Pública (Sucam), em 1984, com a aplicação de Sumitiom (Fenitrotiom) técnico. Em seguida foi experimentada a concentração de 60\%, em óleo de soja e, depois, Sumitiom e Malatiom a 40\%, com resultados satisfatórios. $\mathrm{Na}$ máquina motorizada (Leco) a vazão foi de $127 \mathrm{ml} / \mathrm{min}$ com a viatura a $10 \mathrm{~km} / \mathrm{hora}$, o que equivale, teoricamente, a uma dose de $300 \mathrm{ml} / \mathrm{ha}$. Em favelas da cidade do Rio de Janeiro essa concentrações deram ótimos resultados, quando aplicadas com máquinas portáteis (Micro-gen) e (Hatsuta) com doses de 12 a $21 \mathrm{ml} /$ casa em áreas ingremes e de $4,5 \mathrm{ml} / \mathrm{casa}$ em terrenos planos. Com essas máquinas as aplicaçôes desses inseticidas a $25 \%$, também em favelas, deram resultados razoáveis. Nessas máquinas portáteis há necessidade de conseguir uma modificaçāo que diminua a vazão do inseticida, para melhorar o espectro do tamanho das gotas. Com base na bibliografia disponivel sugere-se novos experimentos com concentrações mais baixas de inseticida.

||||||||||||||||||||||||||||||||||||||||||||||||
* Escole Nacional de Saúde Pública, Fiocruz, Caixa Postal, 926, 20010 Rio de Janeiro, Brasil.

* Superintendência de Campanhas de Saúde Pública, Sucam, 70058 Brasilia, Brasil.

*** Organização Panamericana de Saúde, Av. Pedro II, 278, 20941 Rio de Janeiro, Brosil. 


\section{INTRODUÇÃO}

Enquanto na agricultura a aplicação de inseticidas sobre superfícies foi sempre a regra, na saúde pública, até o advento do DDT, predominou a aplicação espacial que consiste em tornar o ar contido numa casa ou em outra es. trutura, venenoso ou tóxico para os insetos. É claro que em ambos os casos houve exceçôes. Em laranjais dos Estados Unidos foi comum cobrir as árvores com uma lona e fazer desprender, em baixo, gás cianídrico. Por sua vez, a aplicação de Inseticidas contra formas jovens de mosquitos visou sempre a superfície da água.

O expurgo das casas foi usado por Gorgas e por Oswaldo Cruz, para o combate à febre amarela e por Carlos Chagas para o controle da malária $(49,14,9)$. Esses três sanitaristas usaram anidrido sulfuroso, obtido com a queima de enxofre, processo que exigia a cobertura das casas com toldos e a proteção dos objetos metálicos. Para o expurgo de quartos, onde seriam isolados enfermos, Oswaldo Cruz usou a queima de piretro.

Deve-se lembrar que, como quase tudo, a queima de substâncias vegetais para eliminar os mosquitos das habita. ções, já era pratica da na antiga China( ${ }^{29}$ ).

Durante a campanha contra a febra amarela no Rio de Janeiro, em 1928.29, os inconvenientes do trabalho com gás sulfuroso levaram Barreto \& Periassu( $\left.{ }^{2}\right)$ a estudar novas técnicas.

Em 1928 já havia aparecido, no comércio, um inseticida de uso doméstico chamado "Flit", para ser aplicado por uma bomba manual, conhecida como bomba de flit. Essa técnica foi aplicada no Rio de Janeiro, mas dava um rendimento muito baixo. Passaram, então, a usar compressores portáteis, movidos a motor elétrico e a aplicar o inseticida com pistola de pintura. Como o rendimento ainda não era satisfatório, foram adotados compressores movidos a motor a gasolina e montados sobre chassi de caminhão. Esses compressores trabalhavam com 70 libras de pressão e forneciam ar comprimido para 12 pistolas de pintura. Em pouco tempo formava-se uma verdadeira neblina dentro da edificação e, dessa forma, todos os recantos eram atingidos. Era uma técnica semelhante às atuais aplicações de inseticida a ultrabaixo volume, diferindo apenas na concentração do princípio ativo. A maneira de atingir o inseto é a mesma, gotas que, por serem muito pequenas, ficam flutuando no ar e vão atingir os abrigos dos mosquitos. Os inseticidas usados eram o próprio "Flit" ou misturas, tendo como solvente o querosene e uma ou mais das seguintes subs. tâncias: piretro, xilol, cresol, salicilato de metila e tetra cloreto de carbono.

Cadernos de Saúde Pública, R.J., 2(4): 147-166, abr/jun, 1988. 
Essa mesma técnica foi amplamente usada na campa. nha contra o Anopheles gambiae no Nordeste brasileiro. $\mathrm{O}$ inseticida usado era uma mistura de $5 \%$ de concentrado de piretro, $10 \%$ de tetracloreto de carbono e $85 \%$ de querosene ou diesel. Todas as aplicações eram feitas com pistola de pintura. Na zona rural o ar comprimido era fornecido por um compressor portátil, semelhante aos usados, atualmente, na borrifação de paredes. Nas cidades o compressor era movido a motor a gasolina e montado em carroça tracionada por muar. Ligadas a esse compressor, por longas tubulações, funcionavam várias pistolas. Soper \& Wilson $\left({ }^{4}{ }^{9}\right)$ definiam essas pulverizações como nuvens de gotículas minúsculas, isto é, o mesmo que fazem as modernas máquinas de nebulização.

Seguindo o exemplo de Chagas, diversos sanitaristas controlaram a malária, na África do Sul e na Índia, com pulverizações semanais das habitações $(39,13,43)$. Curioso que nenhum deles se refere ao trabalho pioneiro de Chagas (9) que, apenas, recebeu o devido destaque de Soper \& Wilson $\left({ }^{4} 9\right)$.

O aparecimento do DDT muda completamente o sistema de aplicação de inseticidas em saúde pública. Ao invés de visar ao envenenamento de todo o ar contido na habitação, passou-se a aplicar o inseticida nas paredes. De um produto que ficava atuando durante minutos, passou-se a uma substância que permanecia ativa durante meses. Foi a grande revolução da saúde pública. No Brasil, a malária que era controlada em algumas capitais e cidades de importância especial, passou a ser combatida em quase todo território nacional. Em poucos anos o número de casos de malária teve uma redução de $97 \%\left({ }^{12}\right)$ e Aedes aegypti foi, pela primeiva vez, erradicado do país (18).

Apesar da aplicação do DDT ser feita exclusivamente em paredes e outras superfícies existentes na casa, dados de captura de mosquitos mostram que ele também tem ação fumigante, isto é, funciona como uma aplicação espacial. A diminuição do número de mosquitos que freqüentam as casas, depois que elas são dedetizadas, observada com Anopheles funestus na África (36) e com os anofelinos do subgênero Kerteszia no Brasil ( ${ }^{1}$ ), só pode ser resultado da presença de vapores do inseticida na atmosfera da casa.

Em seguida ao DDT, foi desenvolvido outro insetici. da para aplicação em superfícies, o BHC, que também diminui o número de mosquitos que entram nas casas. Este, entretanto, foi bastante usado em aplicações espaciais. Misturado com uma substância comburente, era formula. do sob forma de pastilhas que, queimadas dentro das edificações, distribuíam o inseticida por todo o volume de ar aí

Cadernos de Saúde Pública, R.J., 2(4): 147-166, abr/jun, 1988. 
contido. Ripper (42) informa que o DDT também foi aplicado por essa técnica.

Quando do aparecimento dos inseticidas organoclorados, a aplicação de inseticidas por aviōes e helicópteros, já estava bem desenvolvida na agricultura e, em menor esca. la, na aplicação de larvicidas contra mosquitos, principalmente verde-paris nos Estados Unidos $\left({ }^{6}\right)$. Como era de esperar, o DDT e o BHC foram aplicados com aviões e helicópteros. No caso de criadouros a céu aberto, tratava-se de aplicação sobre superfícies, entretanto, no Brasil eles foram aplicados em florestas e, na realidade, eram aplicações mistas. A poeira dos pós secos e as gotículas das pulverizações ficavam flutuando e podiam atingir todos os pontos da floresta. Esses trabalhos executados em Santa Catarina, contra os anofelinos do subgênero Kerteszia, como todos os trabalhos de controle de anofelinos adultos em áreas com vegetação, foram eficientes quando as florestas eram pequenas. Nas matas que cobriam grandes áreas, em poucos dias havia infiltração de mosquitos vindos das partes não trata. das $(6,17)$.

Já em plena era dos organofosforados apareceu um inseticida muito eficiente, o Diclorvós ou DDVP, que era impregnado em uma placa de resina, a chamada "Vapona". Essas placas liberavam vapores do inseticida, lentamente, durante três meses. Em saúde pública, propriamente dita, foram pouco usadas, mas no controle de insetos visando ao conforto da população tiveram êxito. Durante alguns anos foram usadas nas galerias de águas pluviais da cidade do Rio de Janeiro, para controlar Culex quinquefasciatus ( ${ }^{16}$ ).

Durante a Segunda Guerra Mundial foram desenvolvidas máquinas produtoras de termoneblinas, que depois passaram a ser usadas na aplicação de inseticidas. $O$ antigo Serviço Nacional de Malária fez uma experiência com DDT e com BHC $\left(4^{\circ}\right)$, mas não colocou em prática essa técnica. No tempo do Estado da Guanabara, essas máquinas foram usadas no controle de $C$. quinquefasciatus na cidade do Rio de Janeiro, aplicando Malation. Problemas com o tráfego de veículos, uma vez que a neblina impede a visibilidade, fizeram com que esse método fosse substituído, quando apareceram as máquinas de ultrabaixo volume. Atualmente a Companhia de Limpeza Urbana (Comlurb) da cidade do Rio de Janeiro utiliza máquinas portáteis para eliminar mosquitos em subsolos de edifícios em construção. Nessas máquinas, o inseticida, diluido em óleo mineral (de preferência diesel marítimo) e um cossolvente, se nebuliza ao passar por um tubo aquecido a alta temperatura. Essa técnica, apesar de muito eficiente, não pode ser usada em cidades durante o dia. Além do problema criado para o tráfego, tem aparecido outro pior com as crianças. 
Em São Paulo e em alguns países da América Central tiveram que parar o trabalho porque as crianças iam brincar dentro da nuvem de inseticida.

Antes de passar às aplicações de inseticida a ultrabaixo volume, deve-se lembrar que os aerossóis usados contra insetos caseiros, tornam-se uma medida de saúde pública, quando aplicados em aviões que fazem vôos internacionais, uma vez que destinam-se a impedir a introdução de vetores inexistentes no país de destino.

\section{APLICAÇÕES DE INSETICIDAS A ULTRABAIXO VOLUME (UBV)}

$O$ aparecimento de inseticidas organofosforados de baixa toxicidade abriu campo para uma nova técnica de aplicação, mais econômica e que permite estender o trabatho a grandes áreas rapidamente. São as aplicações de inseticida a baixo e ultrabaixo volume. Sendo que, em saúde pública, praticamente só a última tem sido utilizada.

A UBV é uma técnica nascida em aplicações por via aérea na agricultura. As aplicações convencionais são de baixo rendimento e exigem um grande transporte de água. Isso fez com que, onde possível, fossem substituidas pelas aplicações de pós, os polvilhamentos. O fato dos pós terem pouca aderencia, estimulou a volta às pulverizações, primeiro a baixo volume, onde são aplicados de 40 a 100 litros/ha de calda inseticida $\left({ }^{30}\right)$ e depois a ultrabaixo volume que, nas lavouras, varia entre 0,5 e 5 litros/ha geralmente de produto técnico.

O Conselho Nacional de Saúde ( 11 ) fornece especificaçôes para a aplicação de alguns produtos a ultrabaixo volume, mas não define esse tipo de aplicação. O Departamento de Agricultura dos Estados Unidos (27) considera de ultrabaixo volume, uma aplicação de menos de 4,677 $\mathrm{ml} / \mathrm{ha}$ ( $1 / 2$ galão por acre) e de concentrada, uma formulação contendo $20 \%$ ou mais de inseticida e de produto técnico (tecnical grade) aquelas com mais de $70 \%$. Ainda segundo Lofgren (27), ultrabaixo volume significa a aplicação de pequenas quantidades de inseticidas líquidos em forma concentrada. Outro requisito dessa técnica é o tamanho das gotículas de inseticida.

Himel \& Moore ( 22 ) usando na formulação traçadores fluorescentes, em aplicações por via aérea, mostraram que $93 \%$ das gotículas que se fixavam nos insetos, tinham menos de $50 \mu$ de diâmetro. Isso significa que, na floresta ondc foi feito o trabalho, $95 \%$ das aplicações convencionais con tribuíam para a contaminação do ambiente. Esses autores chamam a atenção para a necessidade de se estudar novos métodos de pulverização e o comportamento das partícu- 
las na atmosfera, pois, Sayer (45) já havia desenvolvido uma máquina para aplicação terrestre a ultrabaixo volume, para o controle de gafanhotos, que chegava a aplicar 300 $\mathrm{ml} / \mathrm{ha}$, mas com gotículas maiores que $40 \mu \mathrm{e}$ com diâmetro mediano de $69 \mu$. Essas aplicações foram feitas com Dieldrim a $20 \%$ e alguns anos depois Skoog et al. (48) aplicaram Malatiom técnico, por via aérea, em pastagens. Essa última teve duas finalidades: uma evitar a contaminação dos animais com um inseticida persistente como o Dieldrim e, outra, diminuir o custo de aplicação para compensar o alto preço do inseticida fosforado.

Todos esses trabalhos foram feitos contra gafanhotos e a primeira aplicação de inseticida a ultrabaixo volume, contra mosquitos, teve finalidade bélica. Durante a guerra do Vietnã foram usadas máquinas costais motorizadas, desenvolvidas pelos militares americanos, para controlar os anofelinos transmissores da malária ( 23 ). Esse trabalho também relata o emprego de Malatiom a $57 \%$, em aplicações feitas com helicóptero a $715 \mathrm{ml} /$ ha e com avião grande a $560 \mathrm{ml} / \mathrm{ha}$. Esses autores referem essas aplicaçōes como a médio volume, porém, de acordo com a norma americana, que também é adotada na agricultura brasileira ( 32 ), elas são a ultrabaixo volume. Essa também foi a primeira aplicação de inseticida fosforado, misturado com solvente, a UBV.

Ó emprego de máquinas portáteis de aplicação a UBV não é muito mencionado na literatura de saúde pública. Só alguns anos mais tarde, Pant et al. (38) relataram o emprego de máquinas portáteis para aplicar Malatiom a UBV, contra $A$. aegypii, em pequenas áreas da Tailândia, que não podiam ser atingidas por veículos. Bastante tempo depois, Sánches et al. (44) aplicaram Fenitrotiom, contra $A$. aegypti, com três tipos de máquinas portáteis. Nesses dois trabalhos as aplicações foram feitas no interior de todos os cômodos das casas. Os resultados foram bons, mas os autores se queixaram da qualidade do equipamento, o que também é mencionado em trabalho recente $\left({ }^{3}\right)$. Além disso, as gotículas eram grandes. A máquina melhor dava um diâmetro mediano de $38 \mu$ e foram medidas gotas até com $150 \mu$ Esse trabalho de Sánchez et al. (44) foi o primeiro a repetir 10 vezes a aplicação do inseticida, o que é indispensável no caso de $A$. aegypti, pois, os ovos existentes nos depósitos vão eclodindo aos poucos $(10)$.

Apesar de, nos Estados Unidos, as máquinas de UBV portáteis não serem populares, a ponto do Center for Disease Control ( $\left.{ }^{8}\right)$ não mencionar esses equipamentos, no Brasil elas têm sido muito úteis. Quando da infestação de Belém por $A$. aegypti, em 1967, os criadouros situados nos buracos das grandes mangueiras que arborizam as avenidas da- 
quela cidade, foram controlados com aplicações de inseticidas fosforados por máquinas de UBV portáteis e, atualmente, elas estão sendo muito úteis no controle desse mosquito nas favelas do Rio de Janeiro.

$O$ presente artigo visa, principalmente, ao controle de mosquitos, mas não se pode deixar de informar que essas máquinas portáteis proporcionaram a primeira técnica própria para a eliminação dos triatomíneos das habitaçōes. $\mathrm{O}$ método convencional de aplicar BHC ou outro inseticida na superfície das paredes, é uma transcrição do sistema utilizado para controlar os anofelinos transmissores da malária, que visa atingir o inseto, quando ele pousa na parede. Para o triatomíneo, entretanto, a parede é um local de passagem quando ele vai se alimentar. $O$ seu local de abrigo são as frestas das paredes ou de outras estruturas, que não são perfeitamente atingidas pela borrifação do pó molhável que é a formulação mais adequada para o caso. Já o jato do aerossol aplicado dentro da casa, contra a parede, tem maior facilidade de penetrar nas frestas e, depois, as gotículas menores que ficam flutuando dentro da casa, podem atingir todos os pontos onde o inseto possa se abrigar. Essa técnica foi desenvolvida na Argentina por Martinez et al. ( $\left.{ }^{31}\right)$ e depois aplicada com êxito, no Brasil, por Sherlock \& Muniz (47).

Lofgren (27) chamava a atenção para a dificuldade de obtenção de equipamento portátil adequado. Atualmente, existem máquinas muito boas, tanto importadas, quanto fabricadas no país, entretanto persiste um problema sério. Como o motor tem que trabalhar em alta rotaçāo, o desgaste é muito grande. Mesmo com boa manutenção a duração das máquinas não é satisfatória. Além disso, essas máquinas são projetadas para a lavoura e a experiência acumulada pela Superintendência de Campanhas de Saúde Pública (Sucam), nas favelas do Rio de Janeiro, tem mostrado que é necessário diminuir a vazão do inseticida e o tamanho das gotículas.

Apesar de bem desenvolvida na agricultura, a ponto da Empresa Brasileira de Aeronáutica (Embraer) fabricar um avião para essa finalidade (o Ipanema), no Brasil não têm sido feitas aplicações de inseticidas a UBV, por via aérea, contra mosquitos. Entretanto, é bom lembrar alguns dados dos Estados Unidos, devido a um certo exagero de parte dos chamados movimentos ecológicos, quanto à questão do uso de inseticidas. Assim é que Gilotra et al. (20) mencionam que só numa epidemia de encefalite, em 1971, foram pulverizados 4,8 milhões de hectares e que, anualmente, são pulverizados nos Estados Unidos cerca de 40 milhões de hectares. Por sua vez, Burgoyne et al. (5) rela- 
tam a aplicação, por via aérea, de Paratiom Etílico em Salt Lake City e declaram que era o praguicida de escolha. A dose não era das mais baixas, 112 a $224 \mathrm{~g} /$ ha e esse é um dos inseticidas mais violentos. Pior que ele só alguns sistêmicos, mas esses são aplicados no interior do solo.

Bem antes do aparecimento das modernas máquinas de aplicação de inseticidas a UBV, já vinham sendo feitos estudos sobre a influência do tamanho das gotículas do inseticida, na sua eficiência. O principal estímulo a essas pesquisas foi a procura de inseticidas capazes de substituir o piretro, cuja produção tornou-se insuficiente para atender as necessidades militares durante a Segunda Guerra Mundial, pois, no Mediterrâneo e no Extremo Oriente, era necessário proteger as tropas contra as moscas e os mosquitos.

Brescia $\left({ }^{4}\right)$ observou que gotículas de $10 \mu$ são eficientes, independente da velocidade do vento e que gotículas de 6 a $14 \mu$ de diâmetro controlam satisfatoriamente Anopheles quadrimaculatus em floresta rala.

Latta et al. (24) já havia calculado, com base na lei de Stoques, que a eficiência de um inseticida para um mosquito pousado era proporcional ao quadrado do diâmetro da gotícula, até o limite de $16 \mu$. Esses mesmos autores, em experiências feitas em túnel de vento, observaram que a eficiência era correlacionada com o produto do quadrado do diâmetro da gotícula, medido em $\mu$ pela velocidade do vento, em milhas por hora $\left(D^{2} v\right)$. Entretanto, isso só era válido quando esse produto estava entre 300 e 1.000 .

Mount ( 33 ) revê a literatura sobre gotículas de aeros. sol, confirma o tamanho ótimo para mosquitos entre $11 \mathrm{e}$ $20 \mu$ e conclui que uma grande parte das gotículas deveriam ser coletadas pelas asas. Isso porque a amputação delas, logo depois da aplicação do inseticida, diminui a mortalidade. Em seguida, Lofgren et al. ( 28 ) borrifando mosquitos com óleo de soja, aplicado com máquina Leco montada sobre viatura e examinando os mosquitos com microscópio eletrônico de varredura verificaram que a naioria das gotículas se depositava nas asas e nas antenas, e que seu diâmetro variava entre 2 e $16 \mu$ Essa deposição nas antenas concorda com os resultados a que chegou Spillman (51), com base em cálculo.

Estudos feitos com cartões impregnados com corante, para verificar o alcance das pulverizações a UBV, mostraram que os mosquitos morrem onde esses cartões não registram nenhuma gota. $O$ fato deles não registrarem gotas com menos de $20 \mu$ é uma indicação de que essas gotículas com diâmetro menor do que $20 \mu$ são da maior importância (27). Por outro lado, a DL 100 (dose que mata $100 \%$ dos insetos expostos) do Malatiom para a espécie usada no en-

Cadernos de Saúde Pública, R.J., 2(4): 147-166, abr/jun, 1988. 
saio (Aedes taeniorhycus) é de $10 \mu \mathrm{g}$, que corresponde a uma gota de $25 \mu$ Como as figuras dadas por Lofgren et al. (28) mostram muitas gotículas nas asas e nas antenas, conclui-se que o mosquito recebe uma superdose, o que, por sua vez, sugere a utilização de formulações menos concentradas, no controle desses insetos.

A primeira referência de aplicação a UBV com diluição é a de Holway et al. ( ${ }^{2}$ ) que, entretanto, não informaram qual foi o solvente utilizado.

Mount \& Pierce ( 35 ) obtiveram bons resultados com Dibrom (Naled) a $10 \%$ em nafta aromática, óleo mineral ou óleo de soja.

Rathburn (41) dá uma relação das formulações de inseticidas, registradas nos Estados Unidos, onde figuram uma de Dibrom a 10\% em nafta aromática ou óleo de soja, para ser aplicada a UBV. Esses registros são para mosquitos e outros dípteros, e neles o Malatiom a UBV figura sempre a $91 \%$. No Brasil há um registro de Naled a $85 \%(19)$, porém nunca foi usado contra mosquitos. Por sua vez o catálogo da Sumitomo dá uma formulação de Sumitiom (Fenitrotiom) UBV a $40 \%$.

Mais recentemente, a Organização Mundial da Saúde (37) informa que, em aplicações a UBV terrestres ou aéreas, - Malatiom a $40 \mathrm{~g} / 1$ e o Pirimifós Metílico a $16 \mathrm{~g} / 1$, em solução oleosa, são eficientes contra mosquitos. Nessa mesma publicação a OMS declara que, contra o $A$. taeniorhyncus, uma solução de Malatiom a 10\% deu o mesmo resultado que o produto técnico. Por área, as doses de ingrediente ativo foram $41 \mathrm{~g} / \mathrm{ha}$ e $249 \mathrm{~g} / \mathrm{ha}$.

No Brasil, até a entrada da Sucam no assun to, só tinham sido feitas aplicações a UBV, contra mosquitos, usando produto técnico puro.

Em todas as máquinas terrestres de UBV o inseticida é pulverizado por pressão de ar mas, recentemente, a Imperial Chemical Industries desenvolveu uma máquina portátil, onde o fracionamento da formulação é feito por uma descarga elétrica. Na agricultura tem sido bastante experimentada, como pode ser visto no Livro de Resumos do $\mathrm{X}$ Congresso Brasileiro de Entomologia, realizado no Rio de Janeiro em 1986. Os resultados sáo bons, porém como as gotas são grandes, com um mínimo de $50 \mu$ e o alcance é pequeno, não servem para mosquitos. Entretanto, seria desejável um aperfeiçoamento dessa máquina, para emprego em favelas, pois, em virtude de não fazerem barulho, não atrairiam as crianças, como fazem as máquinas portáteis motorizadas.

Uma literatura fornecida pela ICI Brasil S.A. dá conta do desenvolvimento de um equipamento para trabalhar 
sobre viatura, onde a pulverização eletrostática é auxiliada por pressão de ar.

Com a mesma finalidade de evitar barulho e, também, os gases da combustão da gasolina, a marinha americana vem experimentando máquinas portáteis acionadas por energia elétrica fornecida por pilhas. As partículas são de bom tamanho, mais de $80 \%$ com menos de $25 \mu$ mas a dispersão do inseticida é por pressão de ar (21).

\section{A EXPERIENCIA DA SUCAM}

Antes da Sucam, a Fundação Estadual de Engenharia do Meio Ambiente (Feema) e a Comlurb vinha aplicando Malatiom técnico a UBV, no controle de $C$. quinquefasciatus na cidade do Rio de Janeiro, usando máquina Leco de medida de vazão por fluxômetro. Que esses trabalhos dão bons resultados é reconhecido pela população, porém, não se dispõe de nenhum dado técnico publicado. Sabe-se, por informação dos responsáveis pelo serviço, que a vazão de inseticida é de $90 \mathrm{ml} / \mathrm{min}$, com a viatura a uma velocidade média de $20 \mathrm{~km} /$ hora e com a pulverização dirigida para o eixo da rua.

A Sucam já vinha aplican do Sumitiom (Fenitrotiom) técnico a UBV, em alguns estados, contra $A$. aegypti, quando em 1984 chegou para a Diretoria Regional do Rio de Janeiro uma máquina Leco de controle de vazão eletrônico. Nessa ocasião, o Prof. José Moquillasa da Organização Panamericana de Saúde, estava dando um curso sobre aplicação de inseticidas e fez a montagem da máquina. Posteriormente o Eng. Davis Waldron, da fábrica Leco, ministrou um curso sobre essas máquinas, com destaque para a resolução de problemas ocorrentes durante a sua utilização. Com base nesses conhecimentos foi iniciado um trabalho experimental de aplicação de inseticidas a UBV, contra o $A$. aegypti.

No primeiro semestre de 1984 , em três bairros do Rio de Janeiro, foi iniciado um ensaio de aplicação de Sumition técnico com máquina Leco \& numa parte mais acidentada de um desses bairros, com máquina portátil Micro-gen. O Sumitiom foi escolhido por ser o único inseticida disponível na Sucam e a utilização do produto técnico puro decorreu da falta de uma experiência anterior. A vazão adotada para a máquina Leco foi de $127 \mathrm{ml} / \mathrm{min}$, com a viatura a $10 \mathrm{~km} /$ hora, o que corresponde a uma dose de $300 \mathrm{ml} / \mathrm{ha}$, num quarteirão quadrado de $100 / \mathrm{m}$ de lado. Com essa vazão e pressão, no compressor, de 3 libras, o DM (diâmetro médio, que corresponde ao diâmetro médio aritmético de Caroll \& Bourg ( ${ }^{7}$ ) das gotículas oscila- 
va em torno de $16 \mu$ com mais de $80 \%$ das gotas com diâmetro inferior a $20 \mu$

Não se tem usado o diâmetro mediano porque, em diversos cálculos feitos, ele diferiu menos de $1 \mu$ do diâmetro médio. Além disso, o importante é a porcentagem de gotas capazes de aderir ao mosquito, isto é, as que têm menos de $20 \mu$ de diâmetro.

A máquina Micro-gen trabalhava com a menor vazão possivel e o DM era da ordem de $30 \mu$

Apenas duas áreas foram tratadas somente com UBV, nas outras houve tratamento focal, que dispensa qualquer medida auxiliar $\left({ }^{26}\right)$. A intenção era verificar uma possivel influência na rapidez com que baixa o índice predial, o que não foi observado. Na área da máquina Leco com 12 aplicaçōes semanais, o índice baixou de $8,6 \%$ para zero e na da Micro-gen de $33 \%$ para $0,5 \%$. Na area testemunha, nesse período de três meses, o índice baixou de $14,8 \%$ para $8,7 \%$. Essa diminuição da positividade, devido à presença do guarda, sem nenhum tratamento, é conhecida desde o tempo do Serviço Nacional de Febre Amarela (50). $\hat{E}$ que as pessoas ficam conhecendo as larvas dos mosquitos e eliminam muitos criadouros.

Em virtude da existência de trabalhos feitos com inseticidas diluídos, montou-se um experimento em que o Sumitiom foi empregado a $60 \%$ de produto técnico, volume/volume, usando como solvente o óleo de soja. Essa escolha do óleo de soja deveu-se, unicamente, ao preço pois, na época, era o óleo vegetal mais barato. Nas máquinas portáteis essa diluição foi feita com xilol bruto cedido, gratuitamente, pela Companhia Siderúrgica Nacional.

Nesse experimento, realizado no segundo semestre de 1984, foi incluída a máquina portátil Hatsuta, que é fabricada no país. A vazão mínima dessa máquina é de $35 \mathrm{ml} / \mathrm{min}$. O DM das gotas colhidas com essa vazão foram de $27 \mu$ para a Micro-gen e $29 \mu$ para a Hatsuta, ambas com a aceleração do motor adotada no trabalho. Na máquina Leco a vazão continuou sendo de $127 \mathrm{ml} / \mathrm{min}$ e o DM das gotas esteve em torno de $16 \mu$

Como a intenção da Sucam na aplicação de UBV, é fazer o fndice predial baixar a menos de $1 \%$, a seguir daremos apenas a concentração do inseticida, o índice prétratamento e o número de aplicações semanais gastas para atingir essa meta.

Leco, Sumitiom técnico, $15,5 \%, 8$ semanas

Leco, Sumitiom $60 \%, 8,4 \%, 3$ semanas

Hatsuta, Sumitiom técnico, 13,9\%, 3 semanas

Hatsuta, Sumitiom $60 \%, 15,2 \%, 5$ semanas

Essa maior rapidez com que baixaram os índices nas aplicações com máquinas portáteis, não é surpresa, pois, 
elas foram feitas em favelas, onde o espaço entre as moradias é tão pequeno que, praticamente, a aplicação é intradomiciliar. Deve-se esclarecer, entretanto, que os aplicadores nunca entraram nas casas. Essa variação no número de semanas que o índice predial leva para baixar, não tem maior significado, pois, ela depende, principalmente, das posturas preexistentes que, aos poucos vão eclodindo, já que a aplicação de inseticidas a UBV é uma medida, fundamentalmente, adulticida.

Esses resultados animaram a diminuir mais a concentração do inseticida e, no início de 1985 , foi planejado novo experimento, onde eles foram aplicados também a $40 \%$.

Como o Sumitiom é importado resolveu-se experimentar o Malatiom, cujo primeiro tambor foi obtido graças a uma gentileza do Dr. Paulino Cabral de Melo, da Comlurb. As diluições, como da vez anterior e das seguintes, referem-se a porcentagem de produto técnico volume/volume. o Sumitiom é a $95 \%$ e o Malatiom a $91 \%$.

A ordem dos dados, apresentados a seguir, é a seguinte: máquina, inseticida e concentração, índice predial prétratamento, número de semanas gastas para fazer o indice baixar a menos de $1 \%$ ou índice atingido depois de 12 aplicações semanais.

Leco, Malatiom técnico, 7,8\%, 4 semanas

Leco, Malatiom 60\%, 12,6\%, em 12 semanas o índice predial chegou a $1,1 \%$

Leco, Malatiom 40\%, 13,6\%, em 12 semanas o índice chegou a $1,1 \%$

Leco, Sumitiom 40\%, 14,0\%, em 12 semanas o índice chegou a $2,9 \%$

Hatsuta, Malatiom técnico, 13,5\%, 12 semanas

Hatsuta, Malatiom 60\%, 18,9\%, 12 semanas

Hatsuta, Malatiom 40\%, 16,3\%, 12 semanas

Micro-gen, Sumitiom técnico, $8,1 \%, 3$ semanas

Hatsuta, Sumitiom $60 \%, 5,0 \%, 8$ semanas

Hatsuta, Sumitiom 40\%, 13,2\%, 12 semanas

Esses dados mostram que, onde não há problema de forma e tamanho dos quarteirões e, também, de arborização, o método é altamente eficiente. É por isso que, nas aplicações feitas com máquinas portáteis nas favelas, o indice desejado, de menos de $1 \%$, foi sempre alcançado ou no prazo programado ou num menor. A falha verificada na área do Sumitiom a $40 \%$ foi provocada, principalmente, pela arborização das ruas e quintais das casas.

Nos trabalhos seguintes não mais se utilizou o xilol como diluente de inseticida, não por questão de eficiência mas porque o xilol danifica certos tipos de pintura. Durante o trabalho não houve nenhuma reclamação, porém, deve-se 
ter em mente que um prejuizo dado a um morador pode gerar má vontade na população, o que seria danoso para o exito do trabalho.

Em virtude dos bons resultados obtidos com a vazão da máquina Leco a $127 \mathrm{ml} / \mathrm{min}$ e, também, da experiência da Comlurb a $90 \mathrm{ml} / \mathrm{min}$, contra $C$. quinquefasciatus, foi planejado um experimento usando essa vazão de 90 $\mathrm{ml} / \mathrm{min}$, a $10 \mathrm{~km} /$ hora e com a mesma pressão de 3 libras no nebulizador. Com essa pressão e vazão, o DM das gotas de inseticida caiu para $15 \mu$ com mais de $90 \%$ das gotas com menos de $20 \mu$ de diâmetro. Esse aumento da porcentagem de gotas capazes de se fixar no mosquito foi, também, leva. do em conta na decisão de experimentar uma vazão mais baixa, apesar da dose por área, $216 \mathrm{ml} / \mathrm{ha}$, ser inferior à dose mínima recomendada para o Malatiom (11).

A área escolhida foi uma parte do bairro de Jacarepaguá habitada por classe média de bom padrão. As ruas são bem arborizadas e as frentes das casas têm muita vegetação. Existem também, na área, conjuntos de edifícios, os chamados condomínios fechados, todos com árvores e jardins. Além disso, alguns quarteirôes são muito irregulares, o que fez com que a dose de inseticida, por unidade de área, fosse muito variável.

As aplicações foram feitas com máquina Leco e as concentrações foram as mesmas da experiência anterior. Os dados, apresentados a seguir, referem-se a inseticida, concentração, índice pré-tratamento e índice encontrado depois de 12 aplicações semanais.

Sumitiom técnico, 8,0\%, 3,0\%

Sumitiom $60 \%, 10,5 \%, 2,8 \%$

Sumitiom $40 \%, 12,0 \%, 3,7 \%$

Malatiom técnico, $8,1 \%, 2,0 \%$

Malatiom $60 \%, 12,3 \%, 3,1 \%$

Malatiom $40 \%, 12,6 \%, 2,4 \%$

Resultados que realmente não são bons, uma vez que a finalidade do trabalho é fazer o indice predial baixar a menos de $1 \%$. Entretanto, esse experimento teve o mérito de mostrar que áreas com muita arborização não devem ser tratadas, unicamente, com máquinas de UBV montadas sobre viaturas, há necessidade de procurar outra solução. De qualquer forma, parece claro que a concentração do inseticida não teve influência no resultado.

No segundo semestre de 1985, a direção da Sucam solicitou um experimento na concentração de $50 \%$, que lhe pareceu mais prudente do que $40 \%$. Aproveitou-se esse trabalho para duas inovações, experimentar a concentração de $25 \%$ na máquina Hatsuta e aplicar com máquina Leco dose por unidade de área. Apesar dos resultados terem 
sido bons, essa última prática não é aconselhável, porque obriga a regular a pressão do nebulizador cada vez que a vazão é alterada. Isso torna-se necessário porque, com o aumento da vazão, as gotas ficam maiores, a não ser que se aumente a pressão do nebulizador. Por exemplo: com 189 $\mathrm{ml} / \mathrm{min}$ e 3 libras, que é a pressão com que a máquina vem regulada da fábrica, o DM sobe para $20 \mu$ e a porcentagem de gotas com menos de $20 \mu$ baixa para $65 \%$. Como na máquina Leco, de controle eletrônico, a mudança de pressão implica em afrouxar e reapertar parafusos, considera-se mais prudente não recomendar esse sistema para a rotina.

Para verificar a dose de inseticida necessária, com base na área a ser tratada, media-se, numa planta em escala, a periferia e a área do quarteirão maior, no conjunto a ser tratado com uma determinada dose. É claro que os quarteirões menores recebiam dose maior, porém, como a concentra. ção era de $50 \%$, havia segurança. Nos mais pequenos foi também medida a periferia e a área, e nenhum deles recebeu dose dupla, que corresponderia a um tratamento normal com produto técnico. A dose adotada para ambos os inseticidas foi de $300 \mathrm{ml} / \mathrm{ha}$, uma vez que é a dose determinada pelo Conselho Nacional de Saúde (11) para o Sumitiom. A dose para o Malatiom pode variar entre $300 \mathrm{e} 1.000 \mathrm{ml} / \mathrm{ha}$. porém, a intenção era comparar os dois inseticidas em condiçōes idênticas.

Para verificar se depois da nebulização ainda perma. neciam mosquitos adultos vivos, colocou-se armadilhas de pneu em casas onde existiam criadouros. Esses pneus eram colocados no dia seguinte à nebulização e retirados na véspera da aplicação seguinte. Apesar de não terem aparecido posturas em nenhum deles, o resultado é prematuro, pois, o seu número foi pequeno. E necessário repetir o experimento com um número muito maior de armadilhas.

Esse ensaio foi feito no bairro de Irajá, que é formado, principalmente, por casas, com raros edifícios. Para cada inseticida aplicado a $300 \mathrm{ml} / \mathrm{ha}$ foi feita uma repetição com a vazâo de $127 \mathrm{ml} / \mathrm{min}$, que é a vazão utilizada, rotineiramente, com a viatura da máquina Leco a $10 \mathrm{~km} / \mathrm{ha}$. Teoricamente, o primeiro método corresponderia a uma aplicação a $300 \mathrm{ml} /$ ha nos quarteirões maiores e mais do que isso nos menores. Já no segundo, os quarteirões de um hectare receberiam essa dose e os maiores menos do que isso. Os resultados mostraram, entretanto, que essa dose maior ou menor não influiu nos índices-obtidos.

Com as máquinas portáteis não é válido calcular a dose por unidade de área, pois, ela vai depender do relevo do terreno e do espaço entre as moradias. Foi por isso que nas áreas íngremes o gasto de inseticida variou entre 12 e 21 
$\mathrm{ml} / \mathrm{casa}$, enquanto que numa favela situada num terreno plano, esse gasto foi de $4,5 \mathrm{ml} / \mathrm{casa}$.

No presente ensaio o Malatiom foi empregado sob forma de Citiom, que é o mesmo inseticida a $91 \%$, porém desodorizado.

Os dados abaixo referem-se a tipo de máquina, inseticida e concentração, dose por área ou vazão por minuto, indice predial pré-tratamento, número de aplicações necessárias para fazer esse índice baixar a menos de $1 \%$ ou índice encontrado depois de 12 aplicações semanais.

Leco. Citiom técnico, 300ml/ha, 12,3\%, 3,0\%

Leco, Citiom técnico, $127 \mathrm{ml} / \mathrm{min}, 15,0 \%, 1,2 \%$

Leco, Citiom 50\%, $300 \mathrm{ml} / \mathrm{ha}, 14,6 \%, 8$ a plicações

Leco, Citiom $50 \%, 127 \mathrm{ml} / \mathrm{min}, 19,6 \%, 12$ aplicações

Leco, Sumitiom técnico, $300 \mathrm{ml} / \mathrm{ha}, 10,7 \%, 8$ aplicaçōes

Leco, Sumitiom técnico, $127 \mathrm{ml} / \mathrm{min}, 10,9 \%, 4$ aplicaçōes

Leco, Sumitiom $50 \%, 300 \mathrm{ml} / \mathrm{ha}, 13,6 \%, 8$ a plicações

Leco, Sumitiom $50 \%, 127 \mathrm{ml} / \mathrm{min}, 9,5 \%, 12$ a plicações

Hatsuta, Citiom $25 \%, 50 \mathrm{ml} / \mathrm{min}, 12,7 \%, 1,0 \%$

Hatsuta, Sumitiom $25 \%, 50 \mathrm{ml} / \mathrm{min}, 12.9 \%, 2.4 \%$

Ao final das 12 semanas, em que durou esse experimento, o indice predial da área testemunha havia baixado de $13,7 \%$ para $10,6 \%$.

Nesse bairro não há arborização capaz de interceptar a nuvem de inseticida, nem grandes ir regularidades nos quarteirões capazes de fazer com que algumas áreas não fossem atingidas pela pulverização. A inconsistência dos resultados decorre do fato da aplicação de inseticida a UBV ser uma medida adulticida. As posturas já existentes, nos depósitos, vão eclodindo aos poucos e a questão de se esgotarem ou não, depende em parte das chuvas, que aumentam o nivel da água dos depósitos e, também, do acaso, pois, como é bem conhecido, os ovos de $A$. aegypti podem levar muito tempo para eclodir $(46,18)$. Os dados obtidos permitem, entretanto, algumas conclusões.

A givestão de se calcular a dose por unidade de área, apesar de mais racional, não parece oferecer vantagem, pois, ora o resultado foi melhor, ora foi pior.

A concentração de $50 \%$ na máquina Leco ainda parece excessiva, pois, tanto com o Citiom a $50 \%$, quanto com o Sumitiom a $50 \%$, o indice predial chegou a menos de $1 \%$ com 8 aplicaçōes. Este fato está de acordo com a bibliografia já mencionada ( ${ }^{37}$ ). Por outro lado, com o Citiom técnico a $300 \mathrm{ml} / \mathrm{ha}$, o índice não desceu abaixo de $3,0 \%$.

Não ficou bem claro o comportamento da concentração de $25 \%$ nas máquinas portáteis Hatsuta. Essas má- 
quinas são muito eficientes em favelas e os índices alcançados, $1,0 \%$ para o Citiom e $2,4 \%$ para o Sumitiom, não foram animadores. Como é vantajoso trabalhar com concen. trações baixas, não só devido à economia como, também, à menor exposição dos aplicadores e moradores ao inseticida, é interessante insistir no assunto. Dois objetivos devem ser procurados: um, conseguir da fábrica uma diminuição da vazão, para melhorar o espetro das gotas e, outro, fazer a aplicação mais lentamente para aumentar a dose por unidade de área.

Tanto esse experimento, como os anteriores, não mostraram nenhuma vantagem de um inseticida sobre outro, apesar do Sumitiom ser considerado um inseticida mais potente que o Malatiom.

No total, os experimentos mostraram que não é fácil obter o desiderato da Sucam de baixar, consistentemente, o índice predial a menos de $1 \%$, com 12 aplicações semanais de inseticida a UBV. Entretanto, índice inferior a 5\%, que é considerado o limiar que permite a transmissão da febre amarela, sempre foi conseguido e, na maioria das vezes, com 8 aplicações. O problema torna-se, portanto, político, manter apenas uma situação onde não possa haver transmissão de febre amarela, com umas 10 ou, no máximo, 12 aplicações de UBV ou tentar atingir um indice sempre inferior a $1 \%$ aumentando o número de aplicaçōes semanais. Em virtude dessa manutenção da positividade ser resultante dos ovos existentes nos depósitos, poder-se-ia pensar em aumentar a periodicidade das aplicações para quinzenais ou mensais. E necessário, entretanto, ter em conta que um prazo maior do que uma semana permitiria que os adultos eclodidos, durante esse período, fizessem novas posturas, pois. no verão do Rio de Janeiro, o ciclo de ovo a pupa pode durar menos de uma semana (25).

\section{AGRADECIMENTOS}

Os autores são gratos aos Inspetores-Gerais Henrique Emilio Nunes Sampaio e Walter Antonio das Neves, pela dedicação com que executaram as suas tarefas e ao Dr. Pelagio Parigot de Souza, Diretor Regional da Sucam, pelo apoio dado ao trabalho. 
The fumigation of insecticides initiated by Gorgas and Oswaldo Cruz had its importance reduced after the introduction of DDT but is use is being resumed with the development of low toxity organophosphate insecticides. At this time, however, the technological development is different. The airplane and the helicopter allowed the spraying of insecticides under the technical grade form and, after that, machines that could be transported in vehicles to perform this task were developed. Soon after, the problem of the size of the droplets was resolved and these must be smaller than $20 \mu$ for mosquitoes. These applications at ultra low volume were initially used in Brazil against Culex quinquefasciatus and its use increased after the reintroduction of Aedes aegypti $A$ series of experimental trials with the aim to produce a rapid decreast in the density of this insect was initiated in 1984 by Sucam using technical grade Sumithion (Fenitrothion). Subsequently it was tried the concentration of $60 \%$ in soybean oil and then Sumithion and Malathion at $40 \%$ with good results. With the machine transported in vehicle (Leco) the flow rate was $126 \mathrm{ml} / \mathrm{min}$ with the vehicle at a speed of $10 \mathrm{~km} / \mathrm{hour}$ which, in theory, corresponds to a dose of $300 \mathrm{ml} / \mathrm{ha}$. At the slums of the city of Rio de Janeiro these concentrations yielded very good results when applied with the aid of portable machines (Microgen and Hatsuta) using doses of 12-20 ml/house in steep areas and $4,5 \mathrm{ml} /$ housein plane areas. With these machines the application of these insecticides in concentration of $25 \%$, also in slums, yelded good results. With the portable machines it is necessary to make modifications to decrease the flow rate of the insecticide to improve the spectrum of sizes of the droplets. Based in the available literature new experiments with lower concentration are suggested.

\section{REFERÊNCIAS BIBLIOGRAFICAS}

1. ARAGĀO, M. B. O comportamento dos anofelinos do subgênero Kerteszia, no sul do Brasil e o efeito do inseticida DDT. Mem Inst. Oswaldo Cruz 72:147-172, 1974.

2. BARRETO, J. B. e Peryassu, A. G. Da aspersão de inseticidas na prophylaxia da febre amarela. Arch $H y g$, Rio de Janeiro 3:405-425, 1929.

Cadernos de Saúde Pública, R.J., 2(4): 147-166, abr/jun, 1988. 
3. BOWN, D. N., Knudsen, A. B., Chukwuma, F. O., Arata, A. A., Ezik, V. L. I wuala, M. O. E. e Bang, Y. H. Indoor and outdoor ULV application of Malathion for the extended control of Anopheles and Aedes species in wooded rural communtties in Nigeria. Mosq Vews 41:136-142, 1981.

4. BRESCIA, F. Salt marsh and anopheline mosquito control by ground dispersal of DDT acrosol. J Econ Entomol 39: $698-715,1946$.

5. BLRGOYNE, W. E., Collett, G. C., Nielsen, L. T. e Gold, R. F. Ecologic factors affecting mosquito control by aircraft in the Great Basin. Mosq. New's 30:361-369, 1970.

6. BLSTAMANTE. F. M., I erreira. M. O. e Rachou, R. G. Da aplcação extradomicliar do DDT por helıcóptero no combate aos anofelinos do subgênero Kerteszia em matas primárias com predominancia de bromélias epífitas. Rev Bras Malar $1: 67-90,1949$.

7. CARROLL. M. K. e Bourg, J. A. Methods of L'LV droplet sampling and analysis: effects on the size and spectrum of the droplets collected. Mosq News 39:645-655, 1979.

8. Center for Disease Control Biologia y control del "Aedes aegypti". Atlanta, Georgia, U.S. Department of health and Human Services, 1980.

9. CHAGAS, C. Prophylaxia do impaludismo (Medidas prophyláticas). Brasil-Médico 20:419-422.1906.

10. CHRISTOPHIRS, S. C. "Aedes aegypti" (L.) The yellow fever mosquito. Cambridge, At the University Press, 1960.

11. Conselho Nacional de Saúde Praguicidas em saúde pública. Brasilla. Centro de Documentação do Ministério da Saúde. 1982.

12. CosTA, J. L. e Bustamante, F. M. Estımativa da incidencia da malária no Brast, no triên to 1950/1952. Rev Bras Malar D Trop 6:597-600, 1954

13. CovEl, G., Mulligan, H. W. e Afrdi, M. K. An attempt to control malaria by destruction of adult mrisquitoes with insecticidal spray. J. Malar Inst India 1:105-113.1938.

14. CRUZ, O. Prophylaxia da fehre amarela. Rio de Janeiro, Typ. do "Jornal do Commercio", 1909.

15.DAVIS, W. A. L. Factors influencing the interation of insecticidal mists and tlying insects. Bull Entomol Res 36:373$393,1946$.

16. DUARTL, J. R. O combate aos mosquitos no sistema de galerias de aguas pluviais através da fumigaçāo de inseticidas. VI Congresso Brasileiro de lengenharia Sanitária. São Paulo. 1971.

17. IERRLIRA. M. O. Rachou, R. G. e Bustamante, F. M. Da aplicação extradomicilar do hexaclorobenzeno por meso de helicóptero no combate aos anofelinos do subgênero Kerteszia, em matas promárias com predomínio de bromélias apífitas. Rev Bras Malar 1:90-99, 1949.

18. IRANCO, O. História da tehre amareia no Brasil. Rio de Janeiro. Minutério dis Saúde. 1969.

19.CALLṼO, D M. Catúlogo dos defensivos agrícolas, i? suplemento, Bracília. Divisão de Produtos Fitossantírios, 1978

20. Gilotra. S. Schulte, W., Anderson. C., Carmichael, G., Stokes. (i. . Ruche, S. Determination of susceptibility of mosquitoes to non-persistent unsetieldes by micro injections. Mosq News 32:358-363. 1972.

21.HAYDE:N, D. L., Schultz, G. W., Ulmer, l. M., Mann, M. O. e Jacohs, R. J. Preliminary field evaluation of portable ULV 
ecuiment. Navy Disease Vector Ecology and Control Center, Jacksonville, Florida, s/d (mimeo).

22. RIMEL, C. M. e Moore, A. D. spruce budworm mortality as a function of serial spray droplet size. Science 156:1250$1251,1967$.

23. HOLWAY, R. T., Morrill, A. W. e Santana, F. Y. Mosquito control activities of the U. S. armed forces in the republic of Vietnam. Mosq News 27:297-307, 1967.

24. LATTA,R., Anderson, L. D. e Rogers, E. E. The effect of particle size and velocity of movement of DDT aerosols in a wind tunnel on the mortality of mosquitoes. J. Washington Acad Sci $15: 397-407,1947$.

25. LIMA, M. M., Amaral, R. S. e Aragão, M. B. Competiçāo de armadilhas para a pesquisa de Aedes aegyptis. Bol Of Sanit Panam em publicação, 1986.

26. LIMA, M. M. e Aragão, M. B. Tratamento focal e perifocal contra Aedes aegypti. Bol Of Sanit Panam em publicação, 1986.

27. LOFGREN, C. S. Ultra low volume applications of concentrated insecticides in medical and veterinary entomology. Ann Rev Entomol 15:321-342, 1970.

28. LOFGREN, C. S., Anthony, D. W. e Mount, G. A. Size of aerosol droplets impinging on mosquitoes as determined with a Scaning eletron microscope. J Econ Entomol 66:1085$1088,1973$.

29.LUH, P. L. Mosquito control in the People's Republic of China. In: Laird, M. e Miles, J. W. eds. Integrated Mosquito Control Metodologies, 1983.

30.MARICONI, F. A. M. Inseticidas tomo I, São Paulo, Livraria Nobel S. A., 1977.

31.MARTINEZ, A., Cichero, J. A., Alania, I. R. e Gonzalez, F. E. Control of Triatoma infestans (Klug) with malathion concentrate, J. Med. Entomol 11:653-657, 1975.

32. MATUO, T. Tecnologia de aplicação de defensivos, In: Graziano Neto coord. Uso de agrotóxicos e receituário agronômico, São Paulo, Agroceres, 1982.

33. MOUNT, G. A. Optimum droplets size for adult mosquito control with space sprays or aerosols of insecticides. Mosq News $30: 70-75,1970$.

34.MOUNT, G. A., Lofgren, C. S., Pierce, N. W. e Husman, C. N. Ultra-low-volume nonthermal aerosols of malathion and naled for adult mosquito control. Mosq News 28:99-103, 1968.

35.MOUNT, G. A. e Pierce, N.W. Adult mosquito kill and droplet size of ultra-low-volume ground aerosols of insectides, Mosq News 32:354-357, 1972.

36. MUIRHEAD-THOMSON, R. C. DDT and gammexame as residual insecticides against $A$ nopheles gambiae in african houses. Trans R Soc Trop Med Hyg 43:401-412, 1950.

37. OMS Métodos químicos de lucha contra artrópodos vectores $y$ plagas de importancia para la salud pública. Ginebra, Organización Mundial de la Salud, 1984.

38.PANT, C. P., Mount, G. A., Jatanasen, S. e Mathis, H. L. Ultralow-volume ground aerosols of technical malathion for the control of Aedes aegypti L. Bull Wld Hlth Org 45: 805817,1971 .

39.PARK ROSS, G. A. Insecticide as major messure in control of malaria, being account of methods and organization put in force in Natal and Zululand during the past six years. Quart Bull Hlth Org, League of Nations, 5:114-133, 1936.

Cadernos de Saúde Pública, R.J., 2(4): 147-166, abr/jun, 1988. 
40. RACHOU, R. G. e Ferrera, M. O. Primeiras provas experimentais com termo-neblinas tóxicas no combate aos anofelinos do subgênero Kerteszia. Rev. Bras Malar 2:23-37, 1950.

41. RATHBURN Jr., C. B. Insecticides for the control of mosquitoes and other dipters. Mosq New 39:58-61, 1979.

42. RIPPER, W. E. Application methods for crop protection chemicals. Ann Appl Biol 42:288-324, 1955.

43. RUSSEL, F. F. e Knipe, F. W. Malaria control by spray-killing adult mosquitoes. J Malar Inst India 2:229-237, 1939.

44.SÅNCHEZ, A. M., Tonn, R., Uribe, L. J. e Calheiros, L. B. Comparación de la eficacia de varios métodos de aplica. ción de inseticidas para el control o la erradicación del Aedes aegypti em Colombia. Bol Of Sanit Panam 84:24-37, 1978.

75.SAYER, H. J. An ultra-low-volume spraying technique for the control of the desert locust Schistocerca gregaria (Forsk). Bull Entomol Res 50:371-386, 1959.

46.SHANNON, R. C. e Putman, P. The biology of Stegomyia under laboratory conditions. Proc Ent Soc Wash 36:185-216, 1934.

47. SHERLOCK, I. A. e Muniz, T. M. Combate ao Panstrongylus negistus com malathion concentrado. Rev Soc Bras Med Trop 9:289.296, 1975.

48.SKOOG, F. E., Cowan, F. T. e Messenger, K. Ultra-low-volume aerial spraying of dieldrin and malathion for rangeland grasshoper control. $J$ Econ Entomol 58:559-565, 1965.

49.SOPER, F. L. e Wilson, D. B. Anopheles gambiae in Brazil, 1930 to 1940. The Rockefeller Foundation. New York City, 1943.

50.SOPER, F. L. , Wilson, D. B. Lima, S. e Antunes, W. S. The Organization of permanent nation-wide anti-Aedes aegypti measures in Brazil. New York, Rockefeller Foundation, 1943.

51.SPILLMAN, J. J. Spray impaction, retention and adhesion. Granfield Institute of Technology, Granfield, Bedford, England, s/d (mimeo). 